Fanum

Sociológico

\section{Forum Sociológico}

Série II

33 | 2018

Número 33

\title{
Devoções populares no Brasil : O ritual de pagamento de promessa a São Gonçalo de Amarante
}

Popular devotions in Brazil: The ritual of promise keeping to São Gonçalo de Amarante

Márcio Douglas de Carvalho e Silva

\section{OpenEdition}

\section{Journals}

\section{Edição electrónica}

URL: https://journals.openedition.org/sociologico/2588

DOI: $10.4000 /$ sociologico. 2588

ISSN: 2182-7427

\section{Editora}

CICS.NOVA - Centro Interdisciplinar de Ciências Sociais da Universidade Nova de Lisboa

\section{Edição impressa}

Paginação: 7-18

ISSN: 0872-8380

\section{Refêrencia eletrónica}

Márcio Douglas de Carvalho e Silva, «Devoções populares no Brasil : O ritual de pagamento de promessa a São Gonçalo de Amarante », Forum Sociológico [Online], 33 | 2018, posto online no dia 30 dezembro 2018, consultado o 29 março 2022. URL: http://journals.openedition.org/sociologico/2588 ; DOI: https://doi.org/10.4000/sociologico.2588 


\title{
DEVOÇÕES POPULARES NO BRASIL: O RITUAL DE PAGAMENTO DE PROMESSA A SÃO GONÇALO DE AMARANTE
}

\section{POPULAR DEVOTIONS IN BRAZIL: THE RITUAL OF PROMISE KEEPING TO SÃO GONÇALO DE AMARANTE}

\author{
Márcio Douglas de Carvalho e Silva \\ - Centro de Educação Aberta e a Distância, Universidade Federal do Piauí (UFPI), Brasil
}

\begin{abstract}
Resumo
A dança de São Gonçalo, muito presente na zona rural do Nordeste brasileiro, é um ritual de pagamento de promessa realizado na forma de dança e cantos. O objetivo deste trabalho é analisar como se dá a relação entre devoto e santo, estabelecida a partir do contrato da promessa, pela qual tanto o santo como o devoto ficam encarregados de cumprir obrigações específicas. São Gonçalo é português e teve seu culto introduzido no Brasil durante o período colonial. Atualmente, a devoção popular a este santo resiste graças aos pagamentos de promessas realizadas por pessoas simples, que, no ato de suas necessidades, recorrem a São Gonçalo na esperança de resolver seus problemas. Conhecido como santo casamenteiro das velhas em Portugal e no Brasil Colonial, atualmente o santo tornou-se um especialista em todas as causas, principalmente curar doenças. A metodologia adotada nesta pesquisa foi a etnografia, que engloba a observação dos rituais de São Gonçalo, entrevistas com os devotos, além de coleta e uso de fotografias.
\end{abstract}

Palavras-chave: dança de São Gonçalo, promessa, ritual

\begin{abstract}
Alsstract
The dance of São Gonçalo, very present in the rural area of the Brazilian Northeast, is a ritual of promise keeping in the form of dance and songs. The purpose of this work is to analyze the relation between devotee and saint, established in the contract of the promise, by which both the saint and the devotee are in charge of fulfilling specific obligations. São Gonçalo is Portuguese and had its cult introduced in Brazil during the colonial period. Nowadays, popular devotion to this saint resists thanks to promise keeping by simple people who resort to São Gonçalo in the hope of solving their problems. Known as the holy matchmaker of old women in Portugal and in Colonial Brazil, the saint has become a specialist in all causes, especially curing diseases. The methodology adopted in this research is ethnography, which includes the observation of the rituals of São Gonçalo, interviews with devotees, as well as the collection and use of photographs.
\end{abstract}

Keywords: dance of São Gonçalo, promise, ritual

\section{Introdução}

Eventos de naturezas diversas fazem com que as pessoas entrem em "contato" com os santos. Alguns para agradecer a pedidos atendidos, outros para solicitar a resolução de um problema, quase sempre de forma imediata. Essa interação, realizada de forma direta, entre os seres humanos e os santos dispensando um intermediário - clérigo ou qualquer representante da Igreja -, é uma manifestação de fé comum no que muitos chamam de religiosidade popular (Leers, 1977), oriunda da junção de elementos religiosos diversos ainda no período em que o Brasil era ligado a Portugal.

Desde o período colonial até os dias atuais, algumas mudanças ocorreram na vivência reli- 
giosa do brasileiro, porém muitos continuam buscando a interferência dos mártires, considerados superiores na tentativa de que estes atendam às suas necessidades. São Gonçalo é um desses escolhidos que teve seu culto introduzido no Brasil pelos seus conterrâneos portugueses. Santo com uma história de vida e um culto que diferenciam-se em muitos casos da maioria das divindades da Igreja Católica. São Gonçalo sempre teve fama de festeiro, sendo talvez esse um dos motivos que possibilitou a sua devoção ter se propagado no Brasil na forma do "culto popular", somada à "habilidade" do santo de realizar milagres. São Gonçalo, que chegou a essas terras séculos atrás como casamenteiro das velhas, hoje é um grande "generalista do milagre", capaz de resolver todos os tipos de problemas.

Com o primeiro registro da devoção a esse santo no Brasil feito pelo viajante francês Gentil de La Barbinais, na Bahia em 1718 (Santos, 2004, p. 230), e citado em várias pesquisas que remetem à era colonial, como a obra de Gilberto Freyre (2006), São Gonçalo se faz presente no imaginário religioso do brasileiro em várias regiões do Brasil até a atualidade. Institucionalizado ou não, ganhou respaldo pelo Brasil e atualmente se faz presente no cotidiano religioso do nordestino ao paulista, apresentando uma demanda ampla de manifestações no ato do seu culto (Cascudo, 1954, p. 434).

A existência do milagre parece ser o elemento propulsor dessa devoção. Após ser solicitada a intervenção e o devoto atendido, este realiza um ritual de agradecimento ao santo conhecido como dança de São Gonçalo. Esse sistema de "trocas de dádivas" (Mauss, 2003, p. 185) concretiza-se pela forma coletiva como a mesma é retribuída, no momento em que o pagador da promessa promove a dança em sua casa e convida a população da região para participar da mesma.

As danças de São Gonçalo tornam-se muito frequentes nos finais de semana entre os meses de junho e dezembro. Além de pagar as promessas, essas danças podem ser vistas como um momento de interação, não só entre "homens e deuses", mas também entre os próprios homens.

Os devotos de São Gonçalo são homens e mulheres habitantes da zona rural do Nordeste brasileiro que possuem vida simples. Vivem quase sempre da agricultura ou da aposentadoria, com poucos recursos financeiros. São pessoas que frequentaram pouco a escola, mas embora o grau de instrução formal não seja muito elevado e alguns dominem pouco a escrita e a leitura, surpreendem muitas colocações de alguns devotos. Durante as entrevistas, defendiam ideias sociais e políticas demostrando boa informação e correta fundamentação. O fato de não saberem ou não terem o hábito da leitura não impede o senso crítico em relação a fatos político-sociais e também religiosos que a "exploração" sugere não desenvolver.

Não me deparei com o estereótipo do devoto "cego" pela religião; conheci pessoas que têm fé acima de tudo, mas conseguem relativizar as possibilidades de não obter "o milagre". Sabem entender porquê podem não o conseguir, afinal, "o milagre não depende exclusivamente do santo, depende da fé que parte da própria pessoa", segundo um devoto.

O objetivo desse trabalho é analisar como se dá a relação entre devoto e santo, estabelecida a partir do contrato da promessa, na zona rural do município de Campo Maior-Piauí-Brasil. Utilizei como principais teóricos Mauss (2003), Durkheim (1996), Turner (2005) e Geertz (2015). A metodologia adotada engloba a observação dos rituais de São Gonçalo, entrevistas com os devotos, coleta e uso de fotografias e análise dos versos das cantigas do ritual.

No ritual de São Gonçalo, a dança aparece como uma forma de reverenciar o santo, mas não só isso; a dança, as cantigas e a conformação espacial do rito revelam um conjunto de símbolos que estão agregados a essa devoção. A dança sempre foi algo muito "familiar" para mim. Embora nunca tenha participado do ritual, sempre o observei de perto, pois na minha infância e adolescência vivia na zona rural onde são comuns essas manifestações religiosas, porém em cada época os interesses e os questionamentos foram mudando até chegar ao olhar de pesquisador, quando comecei minhas indagações sobre esta devoção na graduação. A pesquisa que se observa neste texto estende-se desde o ano de 2009, ainda na licenciatura, e ampliou-se durante a realização do mestrado a partir de 2016, quando parte dos dados para a construção deste trabalho foram coletados em campo.

Por ser uma manifestação que eu supostamente já "conhecia" previamente, tive que buscar analisar este objeto com um olhar diferenciado, agora como pesquisador. Gilberto Velho (1999) aborda a "necessidade" de certo distanciamento do objeto quando este nos é familiar, com o objetivo de realizar uma análise, no mínimo, imparcial. O autor alerta que o familiar nem sempre é conhecido. Essa familiarização não indica necessariamente que conhecemos todos seus aspectos, as suas regras ou a atitude dos sujeitos como participantes de determinada cultura (Geertz, 2015). A incorporação de conceitos, o olhar metodológico, indicam a necessidade de eliminar ou controlar os estereótipos elaborados anteriormente à pesquisa.

Ao longo do trabalho, descobri que aquilo que antes parecia ser familiar guardava segredos e aspectos que até então eu só conhecia superficialmente e olhar a dança de São Gonçalo como um "ritual" que trazia à tona. No trabalho como etnógrafo, o "estar lá" (Oliveira, 1996), etapa descrita na literatura, foi importante na pesquisa; além disso, o olhar, mas, principalmente, ouvir; de forma diferente, apurada 
a certos detalhes. No "campo", esse olhar se fez necessário para assistir "o ritual" e "ouvir" as cantigas. E nas entrevistas não bastou somente olhar e ouvir, pois, descrito o ritual por meio do olhar e do ouvir (suas músicas e seus cantos), ainda faltava a plena compreensão do "sentido" para os devotos que o realizavam, a "significação para o antropólogo que observava em toda sua exterioridade" (Oliveira, 1996, p. 19). Em cada fala dos devotos ao transcrever as gravações, comecei a compreender o quão profunda é a relação destes com o seu santo protetor. Nessas explicações obtidas nas entrevistas - pagadores de promessas, tiradores ${ }^{1}$, cantadeiras e assistentes fui percebendo as nuanças do sentido dado pelos devotos às ações rituais, pois "el trabajo de campo es un ejercicio de papeles múltiples" (Honorio \& Ángel, 2006, p. 23).

Além disso, o "estar aqui" (Geertz, 2009) "escrever" - se mostrou a parte mais surpreendente da pesquisa, pois foi nesta etapa que fui descobrindo aspectos do ritual de pagamento de promessa, agora "para mim" quase nada familiar.

Ao conciliar as falas, cada gesto presenciado no ritual e os versos das cantigas, percebi o sentido para os devotos das várias categorias de promessas e das formas de retribuir o dom sagrado. Para isso, também foi necessário recorrer à memória, não só a memória dos rituais que presenciei enquanto etnógrafo, mas todos os que foram possíveis de serem lembrados ao longo dos anos em que venho presenciando as danças de São Gonçalo. Esse exercício da memória mais antiga com a memória recente foi de extrema importância no momento da escrita porque a "memória constitui provavelmente o elemento mais rico na redação de um texto, contendo ela mesma uma massa de dados cuja significação é mais bem alcançável quando o pesquisador traz de volta do passado, tornando-se presente no ato de escrever" (Oliveira, 1996, p. 31).

Na realização da pesquisa deparei-me com um vasto campo de informações e de possibilidades de interpretação a serem feitas. As dúvidas surgiam em relação a que caminho tomar. Sobre como serem esclarecidas a partir do conhecimento produzido teoricamente no campo antropológico. Foi no olhar e no ouvir novo, ao tentar me afastar do encanto - aquele que a princípio tinha o meu objeto de pesquisa -, que pude tentar escrever um pouco do significado e dos sentidos que a devoção a São Gonçalo tem para cada devoto, colocando no texto o que pude ser capaz de compreender sobre essa manifestação religiosa popular à luz da antropologia.

\section{História de São Gonçalo em Portugal e o seu culto no Brasil}

Santo de origem portuguesa, natural de Tagilde e nascido em 1187, Gonçalo descendia de uma família religiosa e de posses. Teve instrução educacional no Convento de Pombeiro, administrado pelos beneditinos, e de lá seguiu sua formação em Braga, onde estudou teologia e foi ordenado sacerdote. Ao assumir a paróquia de São Paio de Vizela, começa a demonstrar seu desapego aos bens materiais, distribuindo aos mais pobres toda a fortuna que recebeu de herança de seus pais (Fernandes, 1979): "no desempenho do ministério paroquial (...) começou a resplandecer mais brilhantemente em virtudes, com especialidade no zelo apostólico, na castidade e na caridade para com os pobres para com os quais dispendia a maior parte dos rendimentos da igreja" (Brandão, 1953, p. 10).

Após anos de trabalho paroquial, sai em peregrinação rumo a Terra Santa com objetivo de visitar os lugares considerados sagrados pelo cristianismo. Para seguir a sua jornada,

entregou a sua paróquia a um sacerdote seu sobrinho, com a aprovação do ordinário, e seguiu a pé seu rumo, de mãos vazias e coração abrasado de fé. Assim, esfarrapado e faminto, martirizado o corpo mas transbordante de Graça, cumpriu o seu desejo e, passados catorze anos de caminhada, voltou a S. Paio de Vizela. (Fernandes, 1979, p. 202)

Na sua ausência, o seu sobrinho havia apoderado-se dos seus bens e da paróquia. Por articulações de seu substituto, todos tinham conhecimento de que Gonçalo já havia falecido. Após voltar à sua antiga residência e ser expulso pelo sobrinho, Gonçalo busca um novo lugar onde possa viver e dá continuidade ao exercício da sua vocação. Para isso, pediu à Virgem Maria que Ihe mostrasse o melhor caminho a seguir, passando uma quaresma inteira em jejum. Após esse período de penitência, tem uma visão da Virgem que o orienta a ingressar no Convento dos Dominicanos (Brandão, 1953, p. 11).

Depois de grande período entre os dominicanos, Gonçalo dá continuidade à sua vida religiosa em Amarante, onde constrói uma ermida em honra a Nossa Senhora da Assunção, à margem direita do rio Tâmega, de onde "surgiu uma nova fonte de fé e à sua volta se foi aproximando o povo, atraído pela sua ação apostólica" (Fernandes, 1979, p. 203).

Já na velhice, Gonçalo, enfermo, despede-se dos habitantes da sua comunidade, falecendo dia 10 de janeiro de 1259, "em Amarante, no Douro, à margem direita do Tâmega" (Cascudo, 1954, p. 432).

São Gonçalo foi sepultado na sua ermida, onde se encontra a igreja de Amarante. A construção do templo dedicado a São Gonçalo é mais antiga que a sua beatificação, que se concretizou após ter 
precedido três processos, feitos em diversos tempos, foi o último efetuado por D. Rodrigo Pinheiro, bispo do Porto, por ocasião ao Papa Pio, e a instâncias d'el-rei D. Sebastião, do arcebispo de Braga, da Ordem de São Domingos e do povo de Amarante. (Araújo, 2004, p. 28)

Tornando-se beato em 1561 pelo Papa Júlio III, e com um grande empenho do rei de Portugal na época, D. João III, que era devoto de São Gonçalo, seu processo de canonização permaneceu inconcluso apesar do interesse de sua canonização por parte da coroa portuguesa, sendo "considerado no século XVII como o segundo santo português, (atrás apenas de Santo Antônio) por seu caráter nacional e popular" (Santos, 2006, p. 3).

São Gonçalo é português, mas já é um velho conhecido dos brasileiros. Os lusitanos, com os objetivos de colonização do novo mundo, transportaram para sua colônia nos trópicos todos os elementos que firmassem o seu domínio, entre eles a religião. Fazendo-se dessa estratégia, a presença "dos santos é explicada em parte pela missão evangelizadora assumida pela coroa portuguesa e, particularmente, pela ação dos servidores de Cristo - os jesuítas, os membros das ordens monásticas e o clero secular" (Santos, 2004, p. 147).

A partir de então, as manifestações religiosas existentes no Brasil apresentaram em grande parte um legado religioso do medievo trazido para essas terras pelos europeus, aqui incorporando e se remodelando com aspectos religiosos indígenas e de matriz africana, dando corpo a uma religiosidade sincrética provocada em partes pela falta da presença eclesiástica que atendesse as carências espirituais e moldasse a conduta dos cristãos que habitavam esse território. Essas práticas aos poucos transmitiram aspectos para os cultos da Igreja Católica oficial e deles tiraram características. É o caso da dança de São Gonçalo, uma manifestação que mescla elementos dos cultos católicos, africanos e até mulçumanos.

O registro mais conhecido que dá conta da manifestação do culto a São Gonçalo no Brasil data do século XVIII, feito pelo francês Gentil La Barbinais, descrito no seu relato de viagem intitulado Nouveau voyage autour du Monde. A descrição é de 1718, na Bahia, e narra a surpresa de Barbinais com a forma como os brasileiros cultuavam o santo:

Partimos em companhia do Vice-Rei e de toda a Corte. Próximo da igreja dedicada a São Gonçalo nos deparamos com uma imensa multidão que dançava ao som de suas violas. Os dançarinos faziam vibrar a nave da igreja chamada de São Gonçalo [de Amarante]. Tão logo viram o Vice-Rei, cercaram-no e o obrigaram a dançar e pular, exercício violento e pouco apropriado tanto para a sua idade quanto posição: seria porém aos olhos de tal gente um pecado digno do inferno ter ele se recusado a prestar aquela homenagem ao santo cuja festa se celebrava. Tivemos nós mesmos que entrar na dança e não deixou de ser interessante ver numa igreja padres, mulheres, frades, cavalheiros e escravos dançar e pular misturados [pêle-mêle], e a gritar a plenos pulmões 'Viva São Gonçalo do Amarante'. Em seguida, pegaram uma pequena imagem do santo de sobre o altar e começaram a jogá-la para o alto, de um para outro: a bem dizer, faziam o mesmo que os antigos pagãos no ritual que costumavam realizar todos os anos em honra a Hércules, durante o qual açoitavam e enchiam de xingamentos a estátua do semi-deus. (Tinhorão, 2000, p. 135)

A notória habilidade de São Gonçalo em aproximar os sexos, pode ser constatada nas situações onde a prática do culto ao bem-aventurado era possuidora de caráter mais sensual, envolvendo "safadezas e porcarias" (Freyre, 2006). A eficiência em arrumador de casamento para as mais velhas fez com que essas práticas se espalhassem e a intimidade ${ }^{2}$ com o santo aumentasse como no verso abaixo: "Casai-me, casai-me, São Gonçalinho, que hei de rezar-vos amigo santinho" (Freyre, 2006, p. 328).

Somando a esses, outros caracteres de "paganismo" podem ser agregados ao culto de São Gonçalo "além do costume de mulheres estéreis de se friccionarem 'desnudas', pelas pernas a imagem jacente do Bem-Aventurado, enquanto os crentes rezam baixinho e não erguem os olhos para os que não devem ver. $A$ friç̧ão sexual dos tempos pagãos acomodada a formas católicas" (Freyre, 2006, p. 328).

Os relatos que atribuem ao santo amarantino o poder de livrar as mais velhas da solteirice ganham corpo nos versos atribuídos ao santo em Portugal: "São Gonçalo de Amarante, casai-me que bem podeis, já tenho teias de aranha, naquilo que vós sabeis" (Fernandes, 1979, p. 224).

No Brasil, a tradição ${ }^{3}$ de o santo ser casamenteiro das velhas também foi seguida juntamente com sua alegria e sensualidade, como pode ser visto na quadra reportada ao período colonial: "São Gonçalo do Amarante, casamenteiro das velhas, por que não casais as moças? Que mal vos fizeram elas?" (Freyre, 2006, p. 327).

A erotização do culto de São Gonçalo também está ligada aos primórdios da sua devoção ainda em Portugal, onde nas festas do santo "vendiam-se doces com configurações fálicas - os gonçalinhos" (Fernandes, 1979, p. 224). Além disso, os devotos de Amarante "costumavam dar um nó em plantas giestas, o que (...) garantia um próximo casamento. 
Tudo leva a crer que as solenidades de São Gonçalo tenham sido sobrepostas a antigos rituais agrários da fertilidade, de origem pré-cristã" (Cascudo, 1954, pp. 432-433). Outrora, os fiéis dançavam dentro da igreja do Amarante.

A associação do culto do bem-aventurado aos antigos rituais agrários de fertilidade da era pagã, onde a dança aparecia como parte dos cultos que invocavam os deuses para fertilizar a terra e proteger as colheitas ${ }^{4}$, justifica o fato de São Gonçalo ser até a atualidade cultuado em forma de um ritual dançante, uma vez que

a própria bengalinha de São Gonçalo, a que atribuem, quando teria sido atirada ao ar, pelo santo, ao partir escorraçado de Vizela, a virtude de o ter encaminhado para Amarante, faz associar a conjunção fálica, caindo à beira do rio, e fecundando a terra, e fazendo dela brotar uma nova vila (Fernandes, 1979, p. 214).

\section{A dança de São Gonçalo no contexto das festas religiosas}

No Brasil, há uma literatura pertinente de trabalhos que analisaram a dança de São Gonçalo com diferentes enfoques. Na obra Notas sobre a dança de São Gonçalo do Amarante, Brandão (1953) traz uma descrição da dança, iniciando por suas referências em Portugal, mostrando a sua presença no Nordeste Brasileiro e no Centro-Sul do País. O autor apresenta um conjunto de referências das mais variadas naturezas e faz uma compilação de dados sobre a manifestação do culto do santo, dando ênfase à sua manifestação no Estado de São Paulo. O texto, disposto em um pequeno livro, mescla referências documentais e bibliográficas com os dados coletados pelo autor em campo, priorizando a descrição da dança, fazendo ao final uma pequena análise da presença da cultura ameríndia no ritual e da sua função social nas regiões do Brasil onde se apresenta.

Alceu Maynard Araújo (2004) publicou pela primeira vez em 1964 sobre a dança de São Gonçalo, trazendo um vasto histórico sobre a vida do santo, fazendo em seguida sua descrição detalhada acerca da manifestação da dança em alguns municípios de São Paulo como Taubaté, Ubatuba, Tatuí e São Luiz do Paraitinga. Além de descrever o rito, o autor dá ênfase aos movimentos realizados pelos praticantes das danças, e às cantigas comuns a cada região. Na obra, o mesmo trata essa manifestação como uma expressão do folclore sem se preocupar em fazer uma análise mais criteriosa da mesma, restringindo apenas a algumas comparações do material que ele encontrou nas cidades onde observou a dança.

Carlos Rodrigues Brandão (1981), em O ciclo de São Gonçalo, apresenta os versos das cantigas que o mesmo coletou entre os devotos, fazendo também, sempre que possível, comparações, buscando particularidades entre as formas de apresentar a dança. Com uma narrativa fluida, o autor parece querer transportar o leitor para o espaço em que ele fez pesquisa, além disso, não estanca somente na exposição dos aspectos característicos da dança. Na última parte do texto traz a categoria denominada "Estudo", fazendo sua interpretação do elemento que move todo esse sistema de crença, que é a promessa, segundo ele, um "sistema de símbolos e ideologia religiosa no catolicismo popular" (Brandão, 1981, p. 180). Trazendo para junto da sua análise o depoimento dos devotos, Brandão exprime as principais conclusões do mesmo acerca do pagamento das promessas, exemplificando com os casos por ele encontrados na pesquisa de campo, por isso mesmo sendo, dos trabalhos analisados anteriormente, o primeiro a fazer uso de teóricos mais ligados à antropologia, o que deu espaço para uma discussão mais consistente.

Nos trabalhos mais recentes, encontrei principalmente pesquisas que abordam a dança de São Gonçalo em programas de pós-graduação a nível de mestrado em diferentes Estados brasileiros.

Desenvolvida no programa de pós-graduação em Ciências Sociais da Universidade Federal do Rio Grande do Norte, a pesquisa de Glória Cristiana de Oliveira Morais (2005) utilizou como metodologia a etnografia, que trouxe a observação participante, além do uso de fontes históricas sobre a dança na cidade de Portalegre-RN, onde realizou a pesquisa. Neste trabalho, a autora buscou entre os devotos as principais informações da vida de São Gonçalo e as características do rito. A realização da dança fora do contexto da promessa também é algo comum em algumas outras regiões do Brasil, principalmente quando o ritual está associado a algum grupo organizado, como é o caso do povoado Mussuca-SE. A autora ainda situa a importância da dança de São Gonçalo para a construção das relações sociais e para o fortalecimento da memória do grupo e da identidade coletiva.

Em Identidade, memória e narrativas na dança de São Gonçalo do povoado Mussuca (SE), Bomfim (2006) pesquisou o processo de construção da identidade étnica do grupo social que vive no povoado Mussuca. Para isso, o pesquisador investigou os caminhos percorridos pelo rito até o mesmo ser estabelecido como elemento de representação étnica dos grupos que o mesmo identificou como descendentes de escravos. Para realizar sua etnografia, o autor morou alguns messes no povoado, presenciando a prática cotidiana dos moradores da localidade e fazendo entrevistas. Dentro da descrição da sua experiência, o pesquisador abre um amplo espaço para a discussão com as fontes. Partindo dos dados, o mesmo tece algumas considerações 
acerca do que interpretou das danças observadas por ele, destacando o papel politizador que o ritual foi ganhando ao longo do tempo.

O livro A roda de São Gonçalo na comunidade quilombola da Lagoa da Pedra em Arraias (TO), de Teske (2009), aborda devoção a São Gonçalo a partir dos enquadramentos teóricos inscritos no folclore e na comunicação social. É perceptível que o autor adota como metodologia a etnografia e, como ele mesmo afirma, também a história oral, havendo um envolvimento do investigador na vida dos sujeitos na "busca da expressão mais original dos entrevistados" (Teske, 2009, p. 6) ao realizar a pesquisa a partir de questões abertas, tentando diminuir o distanciamento entre pesquisador e pesquisados. Teske aborda de modo geral vários aspectos da comunidade quilombola onde desenvolveu sua pesquisa, como a própria história da comunidade, alimentação, subsistência, educação, estrutura socioeconômica e as tradições religiosas, principalmente no tocante à roda de São Gonçalo, como lá é conhecida.

Situando a dança de São Gonçalo no contexto das festas religiosas, conhecidas por muitos como catolicismo popular, buscamos através da etnografia identificar e analisar os aspectos pertinentes à maneira como esse ritual religioso se apresenta no Estado do Piauí - Nordeste brasileiro; verificando as formas de pensar e viver a religiosidade nessa parte do Brasil, tendo em vista as maneiras como homens e mulheres "negociam" com os santos, como pedem e como pagam as suas dívidas aos seres considerados superiores.

\section{O ritual de pagamento de promessas a São Gonçalo}

Pagar promessa é a contrapartida necessária e obrigatória desse sistema de trocas entre homens e a divindade que se concretiza mediante a realização de um ritual dançante conhecido como "dança de São Gonçalo", promovido pelo beneficiário do milagre, ou de algum representante seu, e executado por "especialistas" na dança. O ritual é o momento onde se torna mais explícito para a comunidade o milagre, pois ele é sinal de que o pedido foi atendido; a promessa, antes um ato particular, torna-se pública e coletiva com a execução da dança.

Ao tecer considerações sobre os ritos, Durkheim (1996), definiu os mesmos como modo de agir de uma sociedade. Os ritos, ora expressos como uma forma de ação religiosa podem ser vistos como "regras que determinam como o homem deve comportar-se com as coisas sagradas" (Durkheim, 1996, p. 24), e nesse contato com o mundo religioso do sagrado o ritual pode ser levado em conta como um mecanismo que tem como função na sociedade o reforço da integração entre os seus membros.
Essa integração suscitada pelo autor está presente no ritual de São Gonçalo, pois é rotineiro amigos, familiares e até desconhecidos do devoto comparecerem à residência do mesmo no dia da dança, para prestigiar a dança, integrando-se com os demais membros da comunidade, pois, nesse contexto,

o rito, portanto, não serve e não pode servir senão para manter a vitalidade dessas crenças, para impedir que elas se apaguem das memórias, ou seja, em suma para verificar os alimentos mais essenciais da consciência coletiva. Através dele o grupo reanima periodicamente o sentido que tem de si mesmo e de sua unidade, ao mesmo tempo, os indivíduos são reafirmados na sua natureza de seres sociais. (Durkheim, 1996, p. 409)

Ao analisar o rito a partir de sua função social, Durkheim (1996) caracteriza esse fenômeno como uma expressão cultural de uma sociedade que empreende o poder de manter a coesão de um grupo, sendo responsável, segundo o autor, pela reanimação periódica e pelo sentimento individual de pertencer a uma dada sociedade.

A promessa é dívida de uma única pessoa, porém para o seu pagamento é necessário que outros membros se façam presentes, pois estes são essenciais para que o rito ocorra, a saber: além do pagador da promessa, o tirador (deve ser do sexo masculino) do "São Gonçalo", este é que define todo o comando da dança, auxiliado por um guia, também do sexo masculino, que auxilia o tirador obedecendo ao seu comando, na fila oposta que se forma em frente ao "arco do santo", onde se realiza a dança, após estes, que tomam a frente das fileiras, vem para cada, um contra-guia, que tem função de obedecer o comando do tirador e do guia, como mostra a Figura 1.

O tirador de São Gonçalo, M., 57 anos, sexo masculino, lavrador ${ }^{5}$, explica como funciona a organização dos membros comandados pelo mesmo:

Nós somos quatro pessoas, eu sou tirador. Do meu lado tem o guia, atrás do meu guia tem o contra-guia, e atrás de mim tem outro contra guia. O guia e os contra-guias tem que me obedecer, tem que ficar prestando a atenção em tudo que eu mando eles fazerem. O comando tudo é comigo, aí atrás vem as cantadeiras.

Percebi que há uma hierarquização das funções entre os participantes, o tirador, por ser considerado uma pessoa mais experiente e conhecedora da estrutura do ritual, comanda todos os demais membros que participam do rito. 
Figura $1 \triangleright$ Posicionamento dos membros da dança de São Gonçalo no ritual

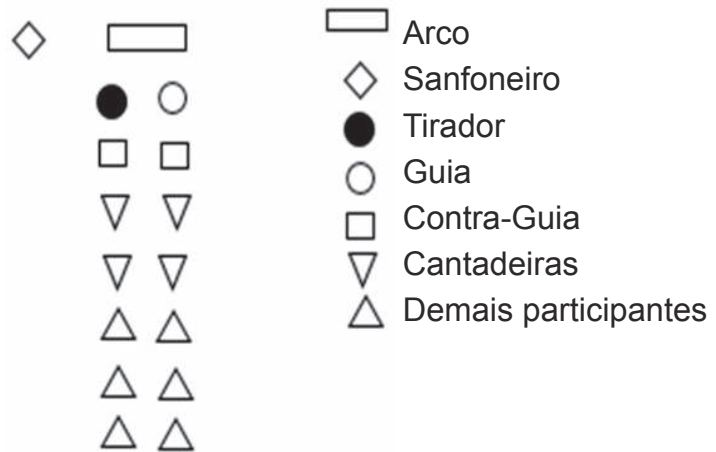

Fonte: Elaborado pelo autor.

Ao fazer uma análise sobre a dança Azande, Evans-Pritchard (1978) afirmou que "a dança, como quaisquer atividades coletivas, gera necessariamente liderança, que tem como função organizar a atividade. ... O prestígio do líder é obviamente condicionado por sua habilidade na composição e no canto das canções" (Evans-Pritchard, 1978, p. 215). Na dança de São Gonçalo, a liderança exercida pelo tirador é sinônimo de prestígio e de respeito pelos demais membros do rito, assim como pelos promesseiros, da mesma forma as cantadeiras, todos têm a sua habilidade prezada, uma vez que "nem todo mundo sabe tirar São Gonçalo".

Após esses quatro personagens do sexo masculino vêm as cantadeiras, todas mulheres, geralmente uma em cada fileira, duas, ou mais, e, após estas, a fila pode ser acrescida por qualquer pessoa que queira participar do ritual, basta que acompanhe os passos "dos que estão comandando". As cantadeiras são, a meu ver, depois do tirador, as peças essenciais na execução desse rito, pois embora não comandem o passo a passo do movimento corporal, comandam com o tom da voz cada etapa que compõe a dança. São elas que sabem e/ou improvisam os versos que dão ritmo ao "vai e volta" das fileiras em direção ao arco de São Gonçalo, como mostra a Figura 2.

Destaco também o tocador de sanfona, instrumento musical também necessário para que as cantadeiras executem "as cantigas de São Gonçalo". Este pode executar seu instrumento com ou sem acompanhante, que quando presente, geralmente um tocador de triângulo ou pandeiro, ficam todos dispostos próximo ao altar do santo, da mesma forma que nas observações feitas por Evans-Pritchard acerca dos azande. No ritual de São Gonçalo "a dança é uma atividade social desenvolvida por pessoas que têm entre si um laço de associação e experiência comuns baseadas na proximidade residencial, e que esse laço é reforçado por sentimentos de parentesco e outras forças socializadoras" (Evans-Pritchard, 2010, pp. 217-218).

Figura $2 \triangleright$ Devotos dançando durante uma jornada da dança de São Gonçalo. Ao fundo, altar (conhecido como arco) com a imagem do santo

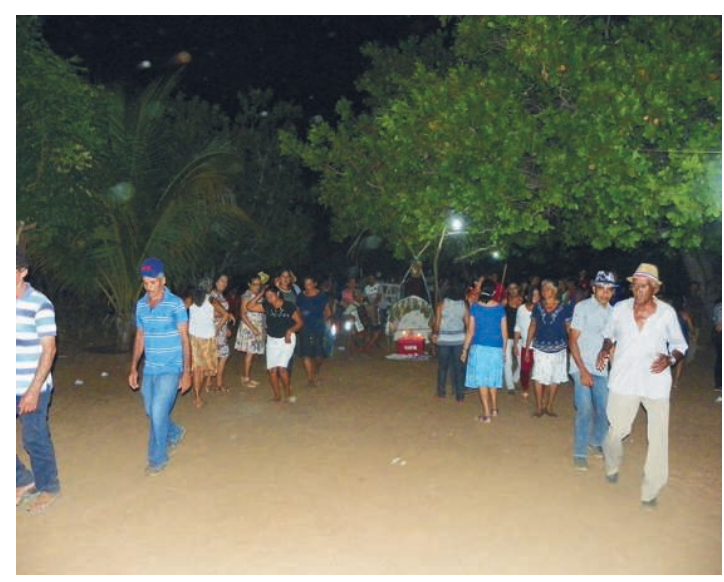

Fonte: Arquivo do autor.

Além dessas pessoas que estão diretamente ligadas à execução do ritual em si, há a participação de muitas outras, como as mulheres que (geralmente) são as principais responsáveis pela preparação das joias que serão leiloadas.

Identifiquei que a função de "conhecedor" (aquele que sabe como realizar as danças, tirar, tocar, cantar) das danças de São Gonçalo é um ofício que se aprende com os "mais velhos", que pode ser ensinado ou aprendido mediante observação. A via familiar é a mais comum, da forma como relata o devoto e tirador de São Gonçalo a quem entrevistei.

Eu acompanhei meu pai. Quando eu nasci meu pai já tirava dança de São Gonçalo. Eu fui acompanhando, fui vendo e fui achando aquilo para mim como uma brincadeira. Em 1983 meu pai adoeceu, e aí ao ver ele sempre que eu tinha muito interesse, perguntou se eu não queria ficar tirando as danças. Eu disse quero! O primeiro São Gonçalo que eu tirei foi em 1984, mês de junho. (M., 57 anos, sexo masculino, lavrador)

Da mesma forma, explica a devota A., 56 anos, sexo feminino, zeladora, que também exerce a função de cantadeira:

Eu aprendi a cantar São Gonçalo, aderi às jornadas e tudo porquê o meu avô era da tradição, aí eu já nasci na tradição dele. Já nasci no berço, porque o meu avô era um 
guiador e a minha avó era uma cantadeira de São Gonçalo. O meu avô era chamado para as regiões que queriam, e a minha avó é que cantava, aí a minha avó se foi, aí era a minha mãe, era as minhas tias, aí eu nasci aprendi e continuo nesse ritmo.

A maior parte dos participantes ativos (aqueles que sabem executar o ritual) já possuem idade acima dos cinquenta anos e, diferentemente da forma como os mesmos aprenderam com os seus pais, os seus filhos não demonstram mais interesse em aprender e dar continuidade a essa função.

Após todos se posicionarem em frente ao arco tem início o ritual. O arco de São Gonçalo é o espaço onde é montado o altar em que é postada a imagem do santo. De estrutura semicircular, o arco é construído com cipós e coberto com tecido no terreiro da casa do pagador da promessa, na seguinte forma:

Figura $3 \triangleright$ Arco de São Gonçalo com imagem do santo

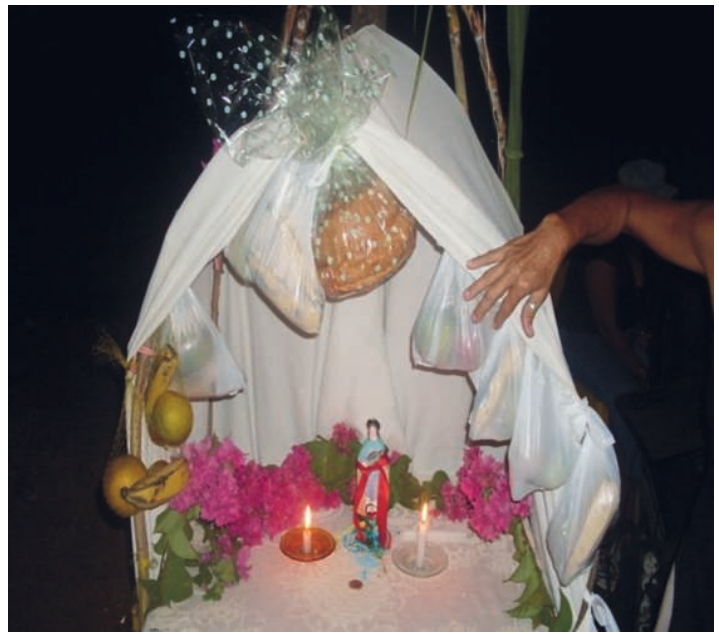

Fonte: Arquivo do autor.

Esse espaço na frente do qual se realiza o rito é parte fundamental dessa estrutura. Dentro do arco é colocado um suporte para colocar a imagem do santo, sendo completado quase sempre com duas velas, em alguns casos algumas flores para enfeitar, podendo ser entendida essa forma de organização do arco/altar como "um programa visual que orienta uma percepção, condição fundamental para emprestar sentido e valor devocional aos objetos, ao espaço, e, por conseguinte, legitimar uma experiência sagrada, resultando da percepção do espaço e da presença, forma e poder dos objetos" (Rocha \& Frid, 2015, p. 243).
O que se denomina "arco de São Gonçalo" carrega um conjunto de simbologias que vão além de um simples altar. Pode ser considerada a casa do santo naquele espaço. É o espelho que se parece(cia) com as casas de muitos devotos pela simplicidade. É o espaço também onde mostra a fartura, a colheita, e onde se mostra solidariedade e respeito, pois ali também se colocam esmolas para "São Gonçalo", por isso mesmo também um local onde a economia monetária se faz presente, pois após o ritual o arco de São Gonçalo é leiloado. É nesse espaço que se reverencia, é na frente dele que se ajoelha, canta, reza e agradece e é também um espaço sagrado. Na percepção do devoto, São Gonçalo está ali e veio para assistir a dança, esses símbolos que o arco agrega em si também fazem parte do ritual e da devoção ao santo.

Turner (2005) deu grande importância aos símbolos que os rituais expressam. Para o mesmo, "o símbolo é a menor unidade do ritual que ainda mantém as propriedades específicas do comportamento ritual; é a unidade última de estrutura específica em um contexto ritual" (Turner, 2005, p. 83). Na sua análise da "estrutura semântica" dos símbolos encontrados no ritual ndembu, percebeu que "cada tipo de ritual pode ser visto como uma configuração simbólica, uma espécie de 'pauta musical', na qual os símbolos são as notas. O símbolo é a menor unidade de uma estrutura específica num no ritual" (Turner, 2005, p. 83).

Partindo dessas concepções poderíamos ver o arco de São Gonçalo como um espaço que conjuga um conjunto de expressões que dizem sobre quem o devoto é, como vive, como pensa, como negocia, como exprime a fé e como se comunica com a divindade. $\mathrm{O}$ arco é simultaneamente um espaço e um tempo. A partir dele o ritual se executa e é com o tempo que dura o ritual que se paga a promessa, respeitando cada etapa que o estrutura.

O cipó que dá forma ao arco tem que ser "da terra", representa a zona rural, e consequentemente o trabalhador, lavrador, o enfeite com cana-de-açúcar, laranja, banana e bolo de goma, representa o que se colhe da terra "porquê São Gonçalo foi um lavrador, era uma pessoa da roça" (M., 57 anos, sexo masculino, lavrador), assim como grande parte dos seus devotos, a "penca do meio" também tem uma conotação diferenciada: todas as frutas e bolos colocados no arco são de São Gonçalo, menos a maior delas que fica centralizada no meio do arco, que é do tirador da dança, uma espécie de recompensa/ reconhecimento pelo seu desempenho no rito.

O arco representa não só o santo que ganhou "trajes de roça", mas também representa o próprio devoto. Para eles, São Gonçalo é aquele homem/ /divindade que eles moldam na mente, e este se parece muito com eles. O ritual é e também simboliza uma festa. É um momento de alegria, de 
agradecimento por algo que deu certo, e também de alívio, por não dever mais ao santo ou por estar cumprindo uma promessa vitalícia, como revelou uma devota: "eu me sinto muito feliz quando vai chegando perto do dia (do ritual), é uma felicidade muito grande pra mim", (R., 67 anos, sexo feminino, aposentada) pois

as festas permitem descobrir oscilações entre uma visão alegre e uma leitura soturna da vida. Permitem igualmente inventar temporalidades, pois promovem uma duração muito rápida. ... Todas as festas recriam e resgatam o tempo, o espaço e relações sociais. ... é na festa que tomamos consciência de coisas gratificantes e dolorosas. (Rocha \& Frid, 2015, p. 83)

Nessa festa, onde o simbólico e o ritual se conjugam, a imagem de São Gonçalo em si também carrega suas simbologias, a mesma é um símbolo sagrado, e é também a representação do sagrado naquele espaço. Geertz afirma que

os símbolos sagrados funcionam para sintetizar o ethos de um povo - o tom, o caráter e a qualidade da sua vida, seu estilo e disposições morais e estéticos - e sua visão de mundo, o quadro que fazem do que são as coisas na sua simples atualidade... (Geertz, 2015, pp. 66-67)

Os símbolos agregados à imagem do santo vão além de representar a realidade do devoto, como, por exemplo, nas vestimentas, a viola que o santo carrega nos braços remonta à sua alegria, o fato de gostar de festa, as noites em que animava as prostitutas para as mesmas não caírem em tentação. A viola só confirma a fama do santo: "São Gonçalo gosta é de festa, de dançar" (P., 67 anos, sexo masculino, lavrador).

Para a realização da promessa e do ritual, quase sempre a imagem de São Gonçalo precisa ser uma já determinada, conhecida dos devotos por ser aquela que realiza milagres. Como há situações em que a promessa é feita para o santo - imagem - (que pode pertencer a um amigo, vizinho ou conhecido), sempre me perguntei para quem de fato se faz a promessa: para São Gonçalo, "o santo" que se acredita que está no céu, ou para a imagem de São Gonçalo que está mais próxima do devoto? Um devoto me deu a seguinte resposta:

O São Gonçalo da região aqui todo mundo se apega com o São Gonçalo da (nome da localidade), então a minha promessa de eu tirar todos os anos com ele. Como eu já tenho compromisso com o São Gonçalo da (nome da localidade) eu tiro um ano com o daqui (imagem que ele possui em casa) e outro com o de lá (imagem de outro devoto que ele considera milagrosa). (M., 57 anos, sexo masculino, lavrador, grifo do autor)

Nessa fala, o devoto explica que ao fazer sua promessa recorreu a um São Gonçalo específico, aquele a quem pediu e aquele a quem prometeu trazer no dia da dança. Poderia acreditar que não restariam dúvidas em relação a que São Gonçalo o devoto faz a promessa, pois seria a imagem, o mais próximo, o da terra mesmo, ainda mais reforçado pelo que continuou dizendo o devoto. Ao fazer o pedido, promete-se ao "santo que vem na sua mente, lá da casa de fulano. No momento do aperreio você vai com o sentido certinho lá" (M., 57 anos, sexo masculino, lavrador). Porém acredito que essa concepção varia de devoto para devoto, pois embora haja predileção por uma imagem determinada - aquela que recorro no momento do aperreio -, pois para esse devoto

\section{todo São Gonçalo é o mesmo, agora tem aquela imagem que você tem mais fé. Eu faço a minha promessa para o São Gonçalo, o tradicional, original, o verdadeiro, mas eu posso pagar com aquele que eu escolhi trazer para o meu altar. (M., 57 anos, sexo masculino, lavrador)}

Aqui a devoto demostra apego aos "dois" São Gonçalos, porém há uma clara distinção entre os mesmos. O verdadeiro, original, pode ser entendido como o São Gonçalo, divindade invisível (e visível pelos seus milagres), e o que "trago para o meu altar" é a imagem, as imagens escolhidas para se fazerem presentes no dia da promessa. Imagens famosas por fazerem milagres são as mais requisitadas, pois

\begin{abstract}
os santos, apesar de estarem no céu, se fazem presentes na terra por meio de sua imagem. É a imagem o objeto de culto e, de algum modo, o santo se identifica com sua imagem. Desta forma, torna-se possível o contato direto entre o fiel e o santo. (Rosendahl, 2015, p. 72)
\end{abstract}

Acredito que essa dualidade entre o divino e o físico depende da concepção de cada devoto, mesmo que de modo geral pareça prevalecer a promessa feita à imagem, e portanto se faria a promessa para uma imagem específica, e seria ela a operadora do milagre! Para justificar minha conclusão, trago até aqui o que os devotos afirmaram ser a grande causadora do milagre, que é a fé, "a promessa é para imagem que é milagrosa. Com a ajuda de Deus e a fé, porquê o que ajuda a gente é a fé" (P., 67 anos, sexo masculino, lavrador). Portanto, se a imagem faz o milagre, este anteveio a fé, e se a imagem ou o santo promoveram a cura, este(s) foi(ram) 
apenas instrumento(s) da fé do devoto, sendo a imagem entendida como um símbolo sagrado dessa devoção, pois

os símbolos sagrados relacionam uma ontologia e uma cosmologia com uma estética e uma moralidade: seu poder peculiar provém de sua suposta capacidade de identificar o fato com o valor no seu nível mais fundamental, de dar um sentido normativo abrangente àquilo que, de outra forma, seria apenas real. (Geertz, 2015, pp. 93-94)

Não seria apenas uma particularização da devoção, mas também uma particularização da divindade, uma vez que é possível ter a mesma em casa, onde é mais fácil de o "santo ouvir", assim como também aqueles que não têm imagem recorrem a imagem do vizinho, ou de outra localidade, para pedir o milagre a este e também prometer trazê-lo até sua casa para realizar a dança. Alguns recorrem a imagem mais conhecida ou a "mais milagrosa", outros preferem o seu "santo de casa":

Eu tenho a minha imagem do meu São Gonçalo bem pequenininho que eu ganhei. Geralmente vão buscar longe. Eu não tinha, antes de eu ganhar esse, eu ia buscar no (nome da localidade), aí uma amiga foi para Canindé e trouxe para mim. (R., 67 anos, sexo feminino, aposentada)

Essa religiosidade, surgida com a ausência de um clero normatizador, ganha formas próprias de expressão, a partir da identificação defendida pelo autor entre mundo social e espiritual. Os santos habitam o mesmo mundo e, se não estão em casa, podem serem pegos "emprestados" de um amigo ou conhecido, perto ou longe de casa, e se for São Gonçalo, o santo anda, e precisa ser solicitado ao seu portador com antecedência.

O primeiro santo (que foi colocado no arco para fazer a dança) veio do (nome da localidade). Os três primeiros foi com essa imagem. Agora, eu já vi a mulher dona dessa imagem e falei com ela, (pedindo a imagem emprestada novamente para uma dança) e ela já disse que está ocupado o mês (outubro) todinho. Tá tudo reservado e não tem vaga não. Ele viaja demais. Esse santo do (nome da localidade), anda em Altos, Castelo, Zé de Freitas, tudo ele anda. As pessoas fazem promessa com ele para aquela imagem lá. Outro homem que tem uma imagem que comprou em Canindé já veio aqui ontem saber se vai ter mesmo São Gonçalo para ele já reservar. (P., 67 anos, sexo masculino, lavrador)
Ter "um São Gonçalo", e principalmente um santo que é requisitado, fazedor de milagre, significa vantagem econômica. Quanto mais "andador" o santo for, melhor, pois isso pode significar que o mesmo é muito milagroso. As relações econômicas entre homens e santos vão além das "trocas" de milagre por dança. Nesse caso, o santo que anda não vai a festa gratuitamente. Assim, como nas igrejas onde os "cofres dos santos" estão sedentos por moedas e cédulas, o São Gonçalo que é levado até um ritual também tem sua compensação em dinheiro. Além das esmolas deixadas ao lado da imagem dentro do arco pelos devotos, o valor arrecadado no leilão do arco também "é de São Gonçalo", além de outras joias que podem ser doadas para o santo no leilão que segue o ritual.

Depois das jornadas tem o arco que é de São Gonçalo. Aí eu vou gritar o arco. Acontece gente que faz promessa com São Gonçalo: "eu vou botar duas joias no meu leilão para São Gonçalo". Quando eu acabo de gritar o arco que eu tenho certeza que é de São Gonçalo, eu vou para o leilão. Aí eu pergunto: você tem uma joia que vai doar para São Gonçalo? "Tenho essa", aí eu grito. Digo para o anotador para pôr o arco de São Gonçalo dá R $\$ 60$, $\mathrm{R} \$ 70$, já deu até cem reais. Aí você põe, aí o arco de São Gonçalo é uma joia. Essas aí são as coisas de São Gonçalo. (M., 57 anos sexo masculino, lavrador)

A economia nessas relações de doação de imagens, como já disse, parece ser um negócio vantajoso para quem tem uma imagem almejada, pois muitas imagens, durante os meses de junho a dezembro, pouco ficam nas suas casas de origem nos finais de semana, sempre sendo levadas de um "São Gonçalo" para outro, e consequentemente levando consigo de volta para casa o dinheiro do leilão do arco, das joias e das esmolas. Aqui encontrei uma visão de concepção dúbia de trabalho, pois, além de "trabaIhar" fazendo o milagre, a imagem que comparece ao ritual está "a trabalho", pois "o pagamento é o que ele ganha no serviço dele, o que tem dentro do altar é dele ... o dinheiro do arco e as esmolas que ele ganhar em fica tudo para o santo" (A., 57 anos, sexo feminino, zeladora). Se São Gonçalo é recompensado duplamente, com as danças e com o dinheiro arrecadado no ritual, e, como sabemos, santo não gasta dinheiro, o dono do ícone certamente é, após o recebedor do milagre, o maior beneficiado nessa crença, assim como o clero da igreja o é.

A esmola aparece nesse sistema como extensão da gratidão à divindade, assim como na igreja os fiéis colocam esmolas nos cofres. Mesmo que não tenha feito uma promessa, colocar uma esmola no arco do santo pode ser entendido como uma 
forma de "ganhar crédito" com a divindade para um pedido futuro, sendo a esmola entendida como "fruto de uma noção moral da dádiva e da fortuna, de um lado, e de uma noção de sacrifício do outro". (Mauss, 2003, p. 208). Doa ao santo quem pode e quem quer, mas é bom colocar suas moedas lá, é um sacrifício pequeno que do ponto de vista simbólico pode valer muito.

Além da "fama" da imagem de ser milagrosa, a quantidade de fitas que amarram ao longo do corpo do ícone é um indicativo visual que revela a eficiência do santo em atender os seus devotos, alguns têm o corpo todo coberto porque "cada fita daquela é um milagre" (R., 67 anos, sexo feminino, aposentada). Além disso, servem "para agradar o santo de alguma forma" (A., 57 anos, sexo feminino, zeladora), como mostra a Figura 4.

Figura $4 \triangleright$ Imagem de São Gonçalo coberto com fitas

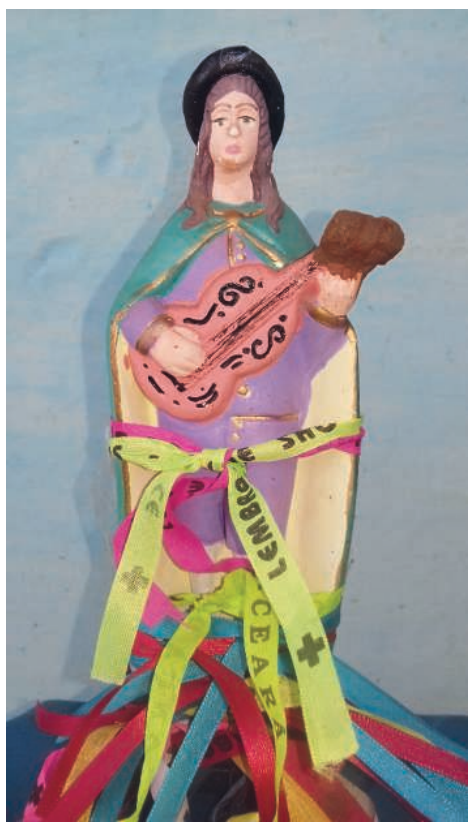

Fonte: Arquivo do autor.

Além de gerar uma renda ao seu portador, os santos vivem no mesmo mundo que os homens, viajam com eles, visitam suas casas e até se comunicam com os mesmos. Cito o caso narrado por um tirador de São Gonçalo, que Ihe foi contado por uma senhora que possui uma imagem de São Gonçalo, com mais de cem anos (de atividade). Muito solicitado na região para comparecer às danças, "o santo não para em casa", a ponto de a sua portadora muitas vezes esquecer que o santo sairá naquele dia, mas nesses casos o santo avisa que "vai pra festa à noite" da seguinte forma:
Se a pessoa faz a promessa e ela não está lembrada que a pessoa vai pegar a imagem no sábado, ela disse que meio-dia o santo avisa ela. Ela ... não tá preocupada se o santo vai sair ... que meio-dia ela escuta umas batucadas dentro do oratório e tem isso como um aviso. (M., 57 anos, sexo masculino, lavrador)

\section{Considerações finais}

Ritual de pagamento de promessa, a dança de São Gonçalo é mais que um "acerto de contas" entre homem e divindade. É uma oportunidade de festejar seu santo protetor, agradecer a graça recebida e talvez até pedir mais milagres. É uma festa que conflui fé, dança, alegria, respeito e submissão ao santo. O local onde é realizada a dança pode ser traduzido como um espaço de sociabilidades, onde amigos e familiares vão para festejar o santo e também demonstrar afeição pelo devoto, pois comparecer à dança na casa do amigo ou parente representa consideração, compadrio.

É uma festa feita pelo homem para o santo e também para os homens. Para o santo, serve para agradecer. Para o homem, serve para sair da rotina do dia a dia. A festa, sempre realizada à noite nos finais de semana, muitas vezes termina já no fim da madrugada, amanhecendo o dia, quando o santo há muito tempo já foi retirado do altar, as cantigas para o mesmo já cessaram, mas a festa teve continuidade.

A dança de São Gonçalo, como um ritual de pagamento de promessa, apresenta-se possuidor de muitos aspectos que podem ser vistos para além do ponto de vista religioso: o leilão que possui uma grande conotação econômica, as festas e/ou serestas que, além do lado econômico, apresentam-se como uma oportunidade da comunidade fugir da rotina diária.

A intenção inicial do ritual é agradecer a um ser divino, reverenciando-o com sua dança e suas cantigas. Nesse momento, não restam dúvidas de que o homem está em contato com o sagrado em um tempo e um espaço que foi criado para agradecer o milagre recebido, mas não só o sagrado penetra esse tempo e esse espaço: a fluidez com que tudo ocorre parece transportar esse mesmo tempo e espaço do mundo sagrado para o mundo profano; não pelas características do rito em si, que possui como elementos, muita música, bebedeiras, danças e gritos, mas pelo que ocorre no seu entorno e que acaba penetrando-o, conjugando sagrado e profano em um diálogo profícuo que parece muitas vezes não se diferenciar. 


\section{Notas}

1 Tirador é a pessoa, geralmente do sexo masculino, que conhece os passos da dança de São Gonçalo e durante a realização do rito é quem orienta os demais participantes a realizarem os passos corretamente.

2 Mott (1997) descreve essas relações de proximidade entre devotos e santos no Brasil Colonial, muitas vezes até física, o que ele chamou de "intimidade com o santo de casa".

3 Ver Hobsbawm (2015).

4 Sobre esse tema ver Ginzburg (1988).

5 Por questões éticas, optamos por identificar os devotos entrevistados pela inicial do primeiro nome, idade, sexo e profissão.

* Texto escrito de acordo com as normas do acordo ortográfico de 1990 .

\section{Referências bibliográficas}

Araújo, A. M. (2004). Folclore nacional II. São Paulo: Martins Fontes.

Bomfim, W. de J. (2006). Identidade, memória e narrativas na dança de São Gonçalo do povoado Mussuca (Dissertação de pós-graduação). Centro de Ciências Humanas, Letras e Artes, Universidade Federal do Rio Grande do Norte, Natal, Brasil.

Brandão, C. R. (1981). Sacerdotes de viola: Rituais religiosos do catolicismo popular em São Paulo e Minas Gerais. Petrópolis: Vozes.

Brandão, G. (1953). Notas sobre a dança de São Gonçalo do Amarante. São Paulo: Comissão Paulista de Folclore.

Cascudo, L. C. (1954). Dicionário do folclore brasileiro. Rio de Janeiro: Ediouro Publicações.

Durkheim, É. (1996). As formas elementares da vida religiosa. São Paulo: Martins Fontes.

Evans-Pritchard, E. E. (1978). Antropologia social da religião. Rio de Janeiro: Ed. Campus.

Evans-Pritchard, E. E. (2010). A dança. Revista de Antropologia Social dos Alunos do PPGAS-UFSCar, 2(2), 208-222.

Fernandes, A. G. (1979). S. Gonçalo de Amarante, seu culto entre portugueses e luso-descendentes do nordeste brasileiro. Ci. \& Tróp., 7(2), 201-236.

Freyre, G. (2006). Casa grande \& senzala. São Paulo: Global.
Geertz, C. (2009). Obras e vidas: O antropólogo como autor (3a Ed.). Rio de Janeiro: Editora UFRJ.

Geertz, C. (2015). A interpretação das culturas. Rio de Janeiro: LTC.

Ginzburg, C. (1988). Os andarilhos do bem. São Paulo: Companhia das Letras.

Hobsbawm, E. (2015). A invenção das tradições. São Paulo: Paz e Terra.

Honorio, M. V. M., \& Ángel, D. de R. (2006). La lógica da investigación etnográfica. Madrid: Editorial Trotta.

Leers, B. (1977). Catolicismo popular e mundo rural. Petrópolis: Vozes.

Mauss, M. (2003). Sociologia e antropologia. São Paulo: Cosac \& Naify.

Morais, G. C. de O. (2005). Entre parentes: Cotidiano, religiosidade e identidade na Serra de Portalegre/ $R N$ (p. 59) (Dissertação de mestrado). Universidade Federal do Rio Grande do Norte, Natal, RN.

Mott, L. (1997). Cotidiano e vivência religiosa: Entre a capela e o calundu. In L. de M. e Souza \& F. A. Morais (Eds.), História da vida privada no Brasil (pp. 155-220). São Paulo: Companhia das Letras.

Oliveira, R. C. de. (1996). O trabalho do antropólogo: Olhar, ouvir, escrever. Revista de antropologia, 39(1), 13-37.

Rocha, E., \& Frid, M. (Coords.) (2015). Os antropólogos: Clássicos das ciências sociais. Rio de Janeiro: Vozes.

Rosendahl, Z. (2015 [1996]). Espaço e religião: Uma abordagem geográfica. Rio de Janeiro: UERJ, NEPEC.

Santos, B. C. C. (2004). A festa de São Gonçalo na viagem em cartas de La Barbinais. Via Spiritus, $11,221-238$.

Santos, B. C. C. (2006). O santo do Bispo. Topoi, $7(13), 300-330$.

Teske, W. (2009). A roda de São Gonçalo na comunidade quilombola da Lagoa da Pedra em Araaias (TO). Kelps.

Tinhorão, J. R. (2000). As festas no Brasil colonial. São Paulo: Editora 34.

Turner, V. W. (2005). Floresta de símbolos: Aspectos do ritual ndembu. Niterói: EdUFF.

Velho, G. (Ed.) (1999). Observando o familiar. In Individualismo e cultura: Notas para uma antropologia das sociedades contemporâneas (pp. 122-134). Rio de Janeiro: Jorge Zaar Ed.

Recebido a 28/01/2018. Aceite para publicação a 01/06/2018.

Márcio Douglas de Carvalho e Silva (conectadonomarcio@hotmail.com). Mestre em Antropologia. Centro de Educação Aberta e a Distância, Universidade Federal do Piauí. CEAD/UFPI, Rua Olavo Bilac,1148 - Bairro Centro, 64.001-280 Teresina - PI, Brasil. 